\title{
ARTICLES
}

\section{A CROSS-SECTIONAL SURVEY TO ASSESS THE LEVEL OF COPING ON MENOPAUSAL SYMPTOMS AMONG POSTMENOPAUSAL WOMEN IN A SELECTED RURAL AREA}

\author{
Ms. Suganthy $\mathrm{C}^{*} \mid$ Dr. Balasubramanian $\mathrm{N}^{* *}$ \\ * Research Scholar in Himalayan University, Itanagar in Arunachal Pradesh, India. \\ **Principal cum Professor, Ambika College of Nursing, Mohali, Punjab, India. \\ DOI: http://doi.org/10.47211/trr.2019.v05i02.010 \\ Received $10^{\text {th }}$ October 2019, Accepted $5^{\text {th }}$ November 2019, Published $20^{\text {th }}$ December 2019.
}

\begin{abstract}
Women need to cope with the changes and the loss that the menopause entails. Coping with the life transition as the menopause is a dynamic process and reflects an ongoing process of engagement by the women with their particular circumstances. Therefore, the study aims to assess the level of coping on menopausal symptoms among postmenopausal women in a selected rural area. The purpose of this study was to quantify the levels of coping on menopausal symptoms adopted by postmenopausal women in a selected rural area. The study was conducted in the Valparai area, after obtaining administrative permission from the village administrative officer of the area and formal written consent from the postmenopausal women who met inclusion criteria. Simple random sampling which is a probability sampling was used to select the samples. A total of 50 postmenopausal women were selected as the samples for study. The high prevalence rates of menopausal symptoms and the relative incapability of them. Symptoms have variable onset concerning menopause. Some women experience symptoms earlier during perimenopause while some experience them at a later time. The application of various coping methods, including the establishment of social support networks, is warranted to enhance postmenopausal women's behaviors in different aspects.
\end{abstract}

Keywords: Level of coping, Menopausal symptoms, Coping strategies \& Postmenopausal women.

\section{ABOUT AUTHORS:}

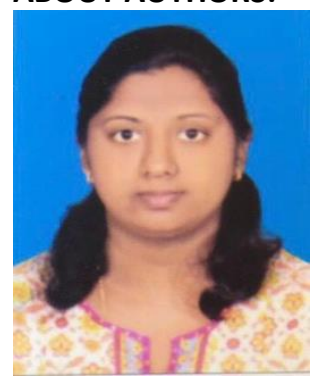

Author, Ms. Suganthy C is a Ph.D. Scholar at Himalayan University, Itanagar, Arunachal Pradesh, India.

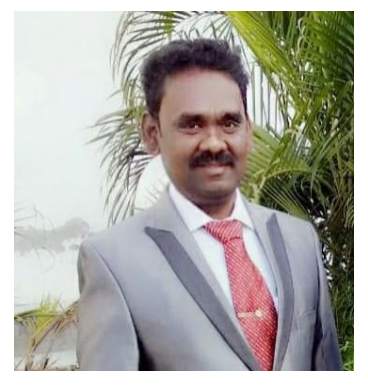

Author, Dr. Balasubramanian N is Principal cum Professor, Ambika College of Nursing, Mohali, Punjab, India. He is Ph.D. Guide at Himalayan University, Itanagar, Arunachal Pradesh, India. He is active researcher with many publications in his name. He has attended and organised various National and International conferences. 


\section{INTRODUCTION}

The word menopause simply refers to the permanent cessation of the menstrual cycle. Menopause has been viewed as a significant change point in women's reproductive and emotional life. Menopause is not a disease but a natural transition in a women's life that results from a decrease in the ovarian production of sex hormones such as Estrogen, Progesterone, and Testosterone. By loss of reproductive potential and transition into later life she may become a victim of both physical and psychological problems. Physical symptoms of menopause include hot flashes, night sweats or chills, sleep disturbances, vaginal dryness, loss of libido, loss of energy, mood swings, increased irritability, loss of skin tone, and urinary incontinence. Psychological symptoms include loss of confidence, depressed mood, irritability, loss of memory, and difficulty in concentrating, panic attacks, and anxiety (Borker S A, et al., 2013). The symptoms of depression and menopause are similar (Olaolorun F M, 2009). Some of the menopausal manifestations experienced by these women can be severe enough to affect their normal daily activities. Unfortunately, the majority of these women are not aware of the changes brought about by menopause. These symptoms directly result from depletion of estrogen levels as women approach the menopausal stage and some of these women begin to experiences these menopausal symptoms early in the perimenopausal phase (Nutan P, et al., 2014).

The common climacteric symptoms experienced by them can be group into vasomotor, physical, psychological, or sexual complaints (Mayo clinic, 2015). In coping with stress, people tend to use one of the three main coping strategies either appraisal focused, problem-focused, or emotion-focused coping. Various coping strategies are adopted by postmenopausal women. Given that quite active physical exercise, awareness on diet and weight with creative activities had been found to help with menopause, this observation is no real surprise. Though studies have been conducted worldwide to explore problems of menopausal women, there hasn't been a huge effort shown in this regard by Indian researchers. In India menopause is considered a normal phenomenon. Women themselves may not seek medical help for problems associated with aging. The majority of the women do not understand the complication and issues associated with menopause. The present study aims to assess the level of Coping on Menopausal Symptoms among post-menopausal women in a selected rural area.

\section{METHODOLOGY}

The design selected for this present study was a cross-sectional survey approach. The study was conducted in the Valparai area which is a hill station surrounded by 64 estate villages. All postmenopausal women in the selected area were the population for the present study. A total of 50 of them were recruited randomly after obtaining a sampling frame from the village health nurse of the area. A lottery method was adopted to draw samples. All the postmenopausal women who met the inclusive criteria were the subjects for the study.

\section{INCLUSION CRITERIA}

The study was limited to the patients who:

- were between the age group of $45-65$ years.

- could speak and understand Tamil

- give the concern to participate in the study

- available during the data collection period

- were not taking any hormonal replacement therapy.

\section{DESCRIPTION OF THE TOOL}

After an exhaustive review, the author developed the tool, based on the objectives. The tool has two sections i.e., Section " $A$ " and Section " $B$ "

- Section " $A$ " consists of demographic data of postmenopausal women.

- Section " $B$ " consisting of a Checklist to assess the level of coping, which comprised of 55 statements under 9 main domains: they are Hot flushes, Urinary changes, Psychological and mood changes, Sleep disturbances, Skin changes, Sexual dysfunction, Brest problems, Risk of skeletal problems, and Risk of heart diseases respectively. The checklist was in Yes or No form. The score for "Yes = 1" was given to positive coping and the negative statement "No = 0" score was given. 


\section{VALIDITY}

Validity refers to the degree to which an instrument measures what it is intended to measure (Patrick Biddix, 2009). Content validity concerns the degree to which an instrument has an appropriate sample of items for the construct being measured and adequately covers the construct domain (Denise. F. Polit, 2008). The content validity of the tool was established from seven experts in the field of Obstetrics and gynecology, Obstetrics and Gynecology Nursing, and psychology. Few suggestions were given by the experts. The tool was modified according to the suggestions and recommendations of experts.

\section{RELIABILITY}

Reliability refers to the degree of consistency or accuracy with which an instrument measures the attribute it has been designed to measure (Katrina B and Roger W, 2009). The reliability of a measuring tool can be assessed in the aspect of internal consistency depending on the nature of the instrument (Paul C, 2013). Correlation of the test was found by using Karl Pearson's correlation coefficient formula and Spearman-Brown formula was used to find out the reliability of the tool, the r-value was 0.78 and it was found that the tool was more reliable.

\section{DATA COLLECTION PROCEDURE}

Formal permission was obtained from the village administrative officer, of the Valparai area. The data was collected by the authors. An average of 3-4 postmenopausal women could be interviewed per day.

The techniques followed during the interview as follows.

- Written consent was obtained from postmenopausal women.

- Instruction related to the tool was given to facilitate cooperation.

- Questions were asked as per the interview schedule.

- Questioning demographic data was asked first as per the interview schedule followed by the question related to coping with menopausal symptoms.

- Each question was repeated as per the interview schedule to help the postmenopausal women to understand and give the correct response.

- At the end of the interview, the question asked by the postmenopausal women were clarified

\section{ETHICAL CLEARANCE}

The study was approved by the research development committee members of Himalayan University, Itanagar, Arunachal Pradesh. Formal permission was obtained by the Village Administrative Officer, Valparai in Coimbatore District. Written informed consent was taken from all the participants. After explaining the purpose of the study, self-introduction and establishment of rapport with the participants were done to gain their co-operation and after that, the postmenopausal women were given the questionnaire.

\section{FINDINGS AND INTERPRETATIONS}

Descriptive statistics and inferential statistics have computed the results by using SPSS software, version 16. The analyses of the data from the study are presented under the following headings:

Section A: Description of the samples according to their demographic variables and menopause specific variables.

Section B: Description of the level of coping among postmenopausal women.

Section C: Association of the level copping with the demographic variables.

Section A: Description of the samples according to their demographic variables. 


\section{ARTICLES}

Table 1: Frequency and percentage distribution of postmenopausal women according to their Demographic variables and Menopause specific Variables

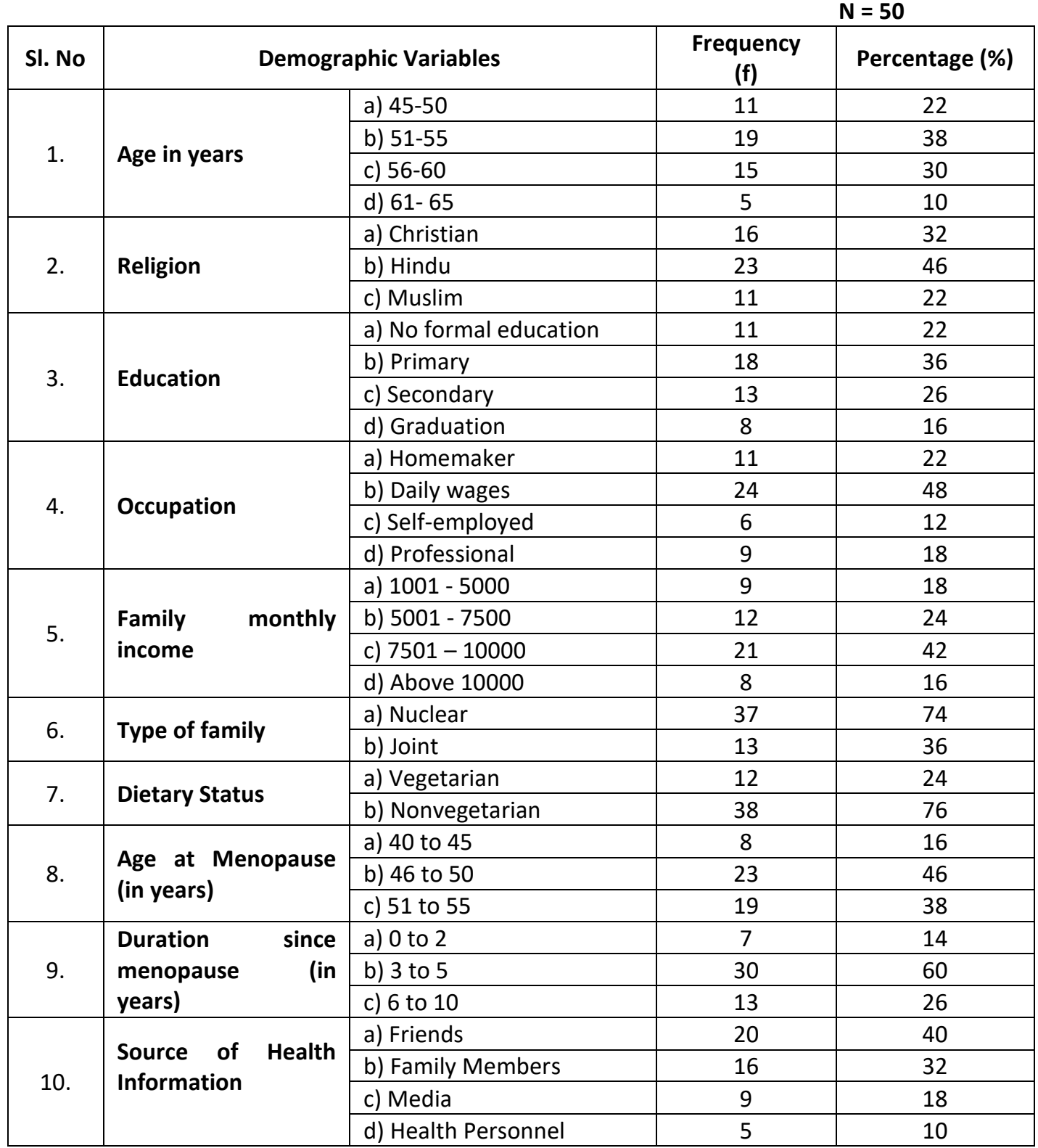

The data presented in Table 1 showed the highest percentage (38\%) of the postmenopausal women were in the age group of 51 - 55 years, $46 \%$ were Hindus, $36 \%$ had primary education, $48 \%$ were daily wages, $42 \%$ had their family monthly income of Rs. 7501 - Rs. 10000, $74 \%$ of them belong to a nuclear family and $76 \%$ of the postmenopausal women were non-vegetarians. The highest percentage (38\%) of the postmenopausal women attained menopause in the age group of 51 - 55 years, the duration of menopause was higher among $60 \%$ of postmenopausal women and $40 \%$ had their source of health information from their friends. 


\section{ARTICLES}

Section B: Description of the level of Coping among postmenopausal women.

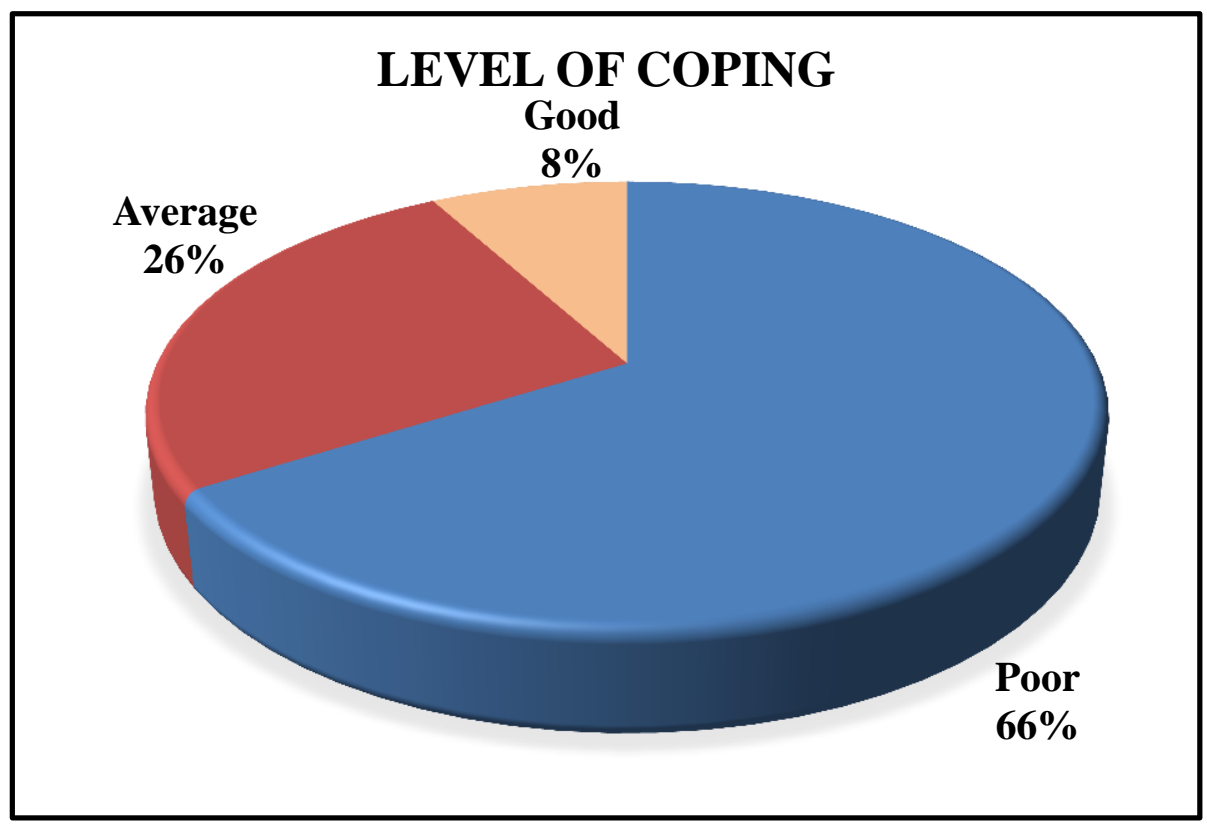

Figure 1 Pie diagram showing the percentage distribution of the level of coping

The data presented in figure 1 shows that $66 \%$ of them had a poor level of coping, $26 \%$ had an average level of coping and only $8 \%$ of them had a good level of coping.

Table. 2: Area wise distribution of Mean, SD, and Mean Percentage of the level of coping score relating to the Menopausal Symptoms.

\begin{tabular}{|l|c|c|c|c|}
\hline \multicolumn{1}{|c|}{ Area } & $\begin{array}{c}\text { Max } \\
\text { Score }\end{array}$ & Mean & SD & $\begin{array}{c}\text { Mean } \\
\%\end{array}$ \\
\hline Hot Flushes & 10 & 2.6 & 0.78 & 26.00 \\
\hline Urinary Changes & 4 & 1.54 & 0.84 & 38.50 \\
\hline $\begin{array}{l}\text { Psychological \& Mood } \\
\text { Changes }\end{array}$ & 11 & 2.78 & 1.06 & 25.27 \\
\hline Sleep Disturbances & 7 & 2.10 & 0.86 & 30.00 \\
\hline Skin Changes & 5 & 1.00 & 0.81 & 20.00 \\
\hline Sexual Dysfunction & 5 & 0.32 & 0.47 & 6.40 \\
\hline Breast Problems & 6 & 1.08 & 0.92 & 18.00 \\
\hline Skeletal Problems & 4 & 1.28 & 0.78 & 32.00 \\
\hline Heart Problems & 3 & 1.60 & 0.61 & 53.33 \\
\hline Overall Score & $\mathbf{5 5}$ & $\mathbf{1 4 . 3}$ & $\mathbf{4 . 9 0}$ & $\mathbf{2 6 . 0 0}$ \\
\hline
\end{tabular}

Table. 2 shows the area wise distribution of the mean, SD, and mean percentage of the level of coping related to menopausal symptoms. In the area "Hot flushes" the mean percentage was $26.00(2.6 \pm 0.78)$, in Urinary changes, the mean percentage was $38.50(1.54 \pm 0.84)$, in Psychological \& mood changes the mean percentage was 25.27(2.78 \pm 1.06$)$, in Sleep disturbances the mean percentage was $30.00(2.10 \pm 0.86)$, in Skin changes the mean percentage was $20.00(1.00 \pm 0.81)$, in Sexual dysfunction the mean percentage was $6.40(0.32 \pm 0.47)$, in Breast 


\section{ARTICLES}

problems the mean percentage was $18.00(1.08 \pm 0.92)$, in Skeletal problems the mean percentage was $32.00(1.28 \pm 0.78)$ and in Heart problems the mean percentage was $53.33(1.60 \pm 0.61)$. The overall mean percentage was $26 \%$.

Section C: Association of the level of Coping with the demographic variables.

Table. 3: Chi-square test showing an association between the level of Coping with the demographic variables among postmenopausal women.

\begin{tabular}{|c|c|c|c|}
\hline \multicolumn{4}{|c|}{$\mathbf{N}=\mathbf{5 0}$} \\
\hline S. No & Demographic data & $\chi^{2}$ value & p-value \\
\hline 1 & Age in years & 8.56 & 0.03575 \\
\hline 2 & Religion & 4.353 & 0.11341 \\
\hline 3 & Educational Status & 4.24 & 0.23669 \\
\hline 4 & Occupation & 15.12 & .00172 \\
\hline 5 & The family income per month & 8.4 & .03843 \\
\hline 6 & Type of family & 11.52 & .00069 \\
\hline 7 & Dietary Status & 13.52 & .00024 \\
\hline 8 & Age at Menopause (in years) & 7.248 & .02668 \\
\hline 9 & $\begin{array}{l}\text { Duration since menopause } \\
\text { (in years) }\end{array}$ & 17.073 & .0002 \\
\hline 10 & Source of Health Information & 10.96 & .01194 \\
\hline
\end{tabular}

The data presented in Table 3 shows the association between mean coping scores and selected demographic variables. Two into two contingency table was used to calculate the association. The Coping scores of postmenopausal women are independent of all demographic variables that are age, religion, educational status. Occupation, family income per month. Type of family, dietary status, age at menopause, duration since menopause, source of health information - it is considered as a not statistically significant for $p>0.005$.

\section{DISCUSSION}

In the present study, high prevalence rates of physical, psychological, and sexual symptoms were noticed which consist of many previous findings (Discigil et al., 2006, Asbury et al., 2006 \& Moustafa, et al., 2015). What is worth pointing out is that the participants in the study did not refer to exercise as a method of relieving the menopausal symptoms. However, this finding can be justified by the old age of the participants in addition to the rural nature of Suhag which does not encourage females to practice exercise. These findings disagree with a study conducted by Asbury et al., (2006) on the importance of continued exercise participation in quality of life and psychological well-being in previously inactive postmenopausal women showed that exercise and physical activity provide a wide range of health benefits for post-menopausal women. The author concluded that healthy postmenopausal women gained significant psychological benefit from moderate-intensity exercise.

In this study, the majority of the participants stated having hot flushes which is one of the most distressing symptoms that women experience as they enter the menopause" and more than half of them could not cope with these flushes. This result agrees with (Yakout et al., 2011) who mentioned that the majority (85.0\%) of women 
have a severe degree of hot flushes. However, the authors cited that hormone replacement therapy was the most effective way of relieving hot flushes. In a study by Loutfy et al., (2006), who surveyed postmenopausal women in Alexandria, hot flushes were the most common symptom exceeding the level of $97 \%$. In the study results, females resorted to having showers and wearing light clothes. The results of the present study also referred to worrisome findings by detecting higher rates of depression and feeling lonely amongst the women and very low rates of coping with such problems. This agrees with study conduct in Egypt by (Moustafa, et al., 2015) (41.2\%) had severed depressed mood which heights from that reported from a study done In Ebril City which revealed to that only (9.4\%) of menopausal women had depressed mood (Gazang \& Jwan 2012) in their study about perception and experience regarding menopause among menopause women attending teaching hospitals in Erbil City. this wide variation related to methodological differences and underestimation of depression in our community due to stigma and shame from mental disorders, However, according to the available literature, Abdul Rahman et al., (2010) \& Yehia et al., (2011) concluded relatively high prevalence rates of psychological problems, especially depression and stress amongst the postmenopausal women.

Moreover, the present study showed that the great majority of females could not cope with urinary incontinence. In general, urinary incontinence is one of the most widespread chronic diseases, posing a social problem in postmenopausal women. Based on its symptoms and causes, several types of urinary incontinence are distinguished: stress incontinence, urge incontinence, mixed incontinence, overflow incontinence, and neurological incontinence. Apart from a disagreeable sensation of uncontrolled urine leakage, sufferers are confronted with a disagreeable odor. The intimate nature of the symptoms and their adverse effect on daily functioning imposes a significant mental burden both on the sufferers and their partners, causing the frustration of many psychological, social and existential needs (Starczewski et al., 2008 \& Yazdkhasti et al., 2015).

\section{CONCLUSION}

The analysis of different cases of the present study shows that menopausal women are not aware of the fact that for many of their psycho-social and physical problems, it is menopause that is responsible, quite often they were attributing these to their calamities. With the increasing life expectancy, women spend almost a third of their life in menopause. Health issues of postmenopausal women therefore would pose a significant challenge to public health also because there has not been a specific health program for such women in the country. The current geriatric health care services are largely based on the general health problems of the elderly and not directed specifically to postmenopausal health problems. Now the time has come for India to develop and start an educational campaign elaborating, Coping strategies for symptoms of menopause among women at all levels of the community.

\section{IMPLICATIONS}

The present study findings have implications for nursing practice, nursing education, nursing administration, and nursing research.

\section{NURSING PRACTICE}

Severe menopause can be identified by the nurse and an appropriate referral should be done. Nurses should have an in-depth knowledge regarding the physiology of menopause, signs, and symptoms of menopause, its management, and the adoption of suitable coping strategies during perimenopause and Postmenopause. When working in a clinical setting, nurses may come across many patients with menopausal symptoms. If the nurse has the knowledge regarding menopause and suitable coping strategies to be adopted during perimenopause and Postmenopause, she can teach this to the clients so that they can achieve a reduction in the menopausal symptoms.

\section{NURSING EDUCATION}

Educational programs regarding awareness of menopause, causes of menopause, signs, and symptoms of menopause and treatment modalities of menopause can be arranged at the nursing school and college level. Interesting and client-friendly learning packages including audio and videos need to be prepared and widely circulated in the nursing schools and colleges. The need for education on the adoption of coping strategies among the menopausal women offers the public health nurse, the auxiliary nurse and midwife, the community health 
nurse, and all-female health workers to promote the positive attitude towards adoption of coping strategies during menopause.

\section{NURSING ADMINISTRATION}

As an administrator, a nurse can arrange in-service education programs for students, staff nurses, and faculty members regarding the adoption of suitable coping strategies during menopause. She can encourage the staff to educate the clients to use coping strategies whenever they come across clients with menopause in hospitals, communities, and other settings. Administrative support and directions need to be given to the teacher in charge of schools and colleges to implement educational programs regarding the management of menopause. Nurses as administrators, women, and competent professionals have a responsibility to promote the right information regarding the adoption of coping strategies during menopausal women.

\section{NURSING RESEARCH}

Menopause is the most common gynecological problem among the middle-aged group. Therefore, it is necessary to conduct extensive research in this field, using a variety of settings and populations. Research can be done to find out more coping strategies among postmenopausal women. It will help reduce the menopausal symptoms and may improve the physical as well as psychological health of the postmenopausal women. There is an increased need for studies regarding menopause at Master's and Post Master's level in various settings in India. Research studies can be conducted on various other aspects of menopause like knowledge related to menopause, attitude towards menopause. The baseline data of this study will be used to educate the menopausal women for adopting suitable coping strategies during menopause.

\section{REFERENCES}

1. Dutta, D. C. (2013). Textbook of Gynaecology. Sixth edition, New Delhi, India: Jaypee Brothers Medical Publishers (P) LTD.

2. Marcus and Kelsey. (2000). Menopause biology and pathobiology. First edition, New York: Academy Press.

3. Shaw's. (1994). Textbook of Gynaecology. XI edition, New Delhi, India: B.I Churchill Livingstone Pvt Ltd.

4. Polit D.F. (2004). Nursing research principles and methods. Seventh edition, Philadelphia: J.B. Lippincott Company.

5. Khan J.A. (2008). Research Methodology. First edition, New Delhi, India: A P H Publishing Corporation.

6. Seema Thomas, Sandhya D'Almeida (2014), Assessment of Psychosocial Problems and coping strategies Among Postmenopausal Women in Selected Communities of Mangalore, International Journal of nursing education and research. Vol.2 (2)

7. Nilimabhore (2015), Coping strategies in menopause women: A comprehensive review, Innovational Journal of Nursing Healthcare. Vol.1(4), 244-253, http://innovationalpublishers.com/Content/uploads/PDF/873386592_IJNHDEC164.pdf

8. Prasanta Kumar Bhattacharya, EnuBoro, MD Jamil, and Aakash Roy (2016), Effectiveness of SelfInstructional Module on Coping Strategies of Tri-Dimensional Problems of Premenopausal Women - A Community Based Study, Journal of clinical and diagnostic research. Available from: 10.7860/JCDR/2016/23530.8935

9. Anil K.Agarwal, Nirmala Kiron, Rajesh Gupta, Aditi Sengar, Preethi Gupta (2018), A study of assessment of menopausal symptoms and coping strategies among middle-aged women of North Central India, International Journal of Community Medicine and Public Health. Vol.5 (10), http://dx.doi.org/10.18203/2394-6040.ijcmph20183995

10. Dipali Ingale (2019), A study on coping strategies adopted by menopausal women residing in selected areas, International Journal of Advanced Scientific Research. Vol.4 (3), 26-28.

11. http://www.ncbi.nlm.nih.gov/pubmed. 